\title{
SURVEY AND APPROACH TO RESTORATION OF DAMAGED BUILDINGS
}

\author{
H. W. Yeatman*
}

One of the major problems confronting any Authority after devastation by fire, flood, storm or earthquake, is the restoration of buildings back to their normal functional use as quickly and efficiently as permissible under prevailing circumstances so that undue hardship, frustration and inconvenience are minimised and alleviated as soon as is humanly possible.

Several factors contribute to failure of buildings, those occurring at Inangahua were not unusual when consideration is given to the circumstances under which the settlement was established.

In the initial stages, although some isolated farm houses existed, the area was selected as a railhead site and in consequence several of the buildings were either transported there or built with a short term life or temporary use in view. However, as is inevitable, some of these buildings remained as accommodation for maintenance staff, or were bought cheaply and re-used on the existing sites or elsewhere in the area as baches and in some cases as permanent accommodation generally by people who could not afford or did not need a more elaborate form of dwelling.

Such an area lacked the essential need for conformity to any County planning scheme and, too, any clear requirement of the controlling authority for the removal of temporary structures whether the buildings be sub-standard in design construction or contrary to the present Building Code requirements in other ways.

The initial formation of this temporary camp settlement and its subsequent contribution towards permanent accommodation forms the basic factor to which can be attributed a considerable degree of the damage incurred, aggravated by other conditions such as deferred maintenance, low bearing quality sub-soil and inadequate drainage. Farm buildings, commercial buildings and some state buildings built before and after the establishment of the camp also indicate the use of poor quality materials and the requirement of some or better supervision; many of these factors were evident from an on site inspection and are dealt with in some detail concerning the restoration work outlined in the following.

\section{Survey procedure of damaged buildings}

First and foremost a quick appraisal of the disaster area at Inangahua was made by helicopter reconnaissance to check on the extent of the damage and accessibility to the various properties. As several different parties were eventually to be interested in restoration works, a common means of references was essential to avoid misunderstandings and unrelated information. To this end a free-hand map of the affected area was prepared, detailing all buildings in general relation to roads, railway, river and one another. All buildings were shown on the map as numbered squares and a list was prepared, stating the name of the owner, name of the occupier and any other relevant information such as present contact address, intenti on of return to the area, etc., with a view towards restoring the properties in some order of priority such as farmers first since they had a livelihood to maintain; services - such as water pumping plant, electrical and communication; commercial concerns such as Transport, shops; dependent workers engaged as farm hands, state employees and assistants in commercial concerns with buildings such as the school and churches following later. However, this arrangement had to be changed and work expedited according to the establishment of insurance cover. 
Considerable assistance in compiling the lists of residents was of fered by local people to whom we were grateful; these lists were duly corrected and brought up to date as more information was gained daily so that a definite and reliable reference chart was quickly established. This chart was gradually expanded to include the name of the Insurance Company together with the value of Insurance cover, assessed value of damage and the ultimate intention of the insured person in the form of cash settlement or Building contractors quote for re-instatement of the property.

Simultaneous with the preparation of the reference map and personal listing, assessment of damage to each property was commenced by two teams each consisting of two M.O.W. buildings overseers who listed damaged work in tabular form similar to the procedure adopted by Department Quantity Surveyors except that time and material were listed separately. All available daylight hours and means of access were taken advantage of for field work. The extensi on of work and subsequent costing being done during the evening up to a very late hour in many cases, so that prospective contractors would have an early opportunity to commence work.

Within three days of the M.O.W. team setting up office in Reefton, Work Schedules were in the course of preparation - these incorporated the map reference number of the building, the name of the owner/occupier and the extent of work required externally and internally room by room.

Competitive quotes were initially decided on but due to processing and subcontractors delays this method was quickly abandoned in favour of negotiation on the site between contractor and the writer. The advantage of this was that each contractor entering the work field was assured of work at an agreed price, able to commence immediately on state contracts and on private buildings by agreement with the owner as well as receive an equitable share of work available.

The method adopted was quickly accepted and worked well. However, the overall quantity of work was dependent on two conditions, firstly - what the private owner wanted deleted from the original assessment with certain new work included and secondly - whether all work desired or even assessed could be done within the amount of insurance available for, with two possible exceptions, none of the residents could afford to borrow extra money for repair work.

To ensure that what they did receive would go as far as was economically possible, non-essential chimeys were deleted and in some cases internal decoration was regarded as a job they could do themselves so that a more important service such as sewerage could be restored (an item not covered by insurance).

The restoration of Government Departmental buildings presented no real problems, since this was undertaken on the advice of the Department concermed.

\section{Type of damage}

Damage to buildings fell into categories:

(a) Structural - Foundations mainly consisted of silver pine piles since these were readily available in the area; advantage of their use, however, had little consideration since they vary in size from 4" diameter to 12 " $\times 6$ " and in length from $4^{\prime \prime}$ above ground to $30^{\prime \prime}$.

In the majority of cases, piles were not connected to the wall plates or bearers by anything more stable than $23^{\text {"I }}$ or $4^{\text {"I }}$ nail which had long since rusted beyond its prime function. 
Pile spacing, too, in relation to cross-sectional dimension of plates and bearers was grossly inadequate in several cases. Additionally, little regard had been given to the poor load bearing value of the sub-soil. It is perhaps timely to mention here that in those cases where both timber and concrete piles had to be straightened and/or levelled up, they were set in an $18^{\prime \prime} \times 18^{\prime \prime} \mathrm{pad}$ of dry mix concrete where this was possible.

Local aggregate is of poor quality and generally unsuitable for good quality concrete, the nearest reliable source being Greymouth.

Many of the concrete piles and some of the foundation corners built on both private and Departmental residences are of interior materials consisting mainly of too large an aggregate with very little bonding. This was noticeable - also in one particular residence which was structurally sound apart from its foundation. This was on a sloping aite having a frontage foundation of approx. $12^{\prime \prime}$ high and rear wall approx. $7^{\prime} 6^{\prime \prime}$ in height, side foundations broken in continuity were $50^{\prime}$ in length with no cross tie walls. All concrete work was sitting on the surface of the ground, very skimpily reinforced and infrequently attached to the building.

Similarly the piles varying in length from $12 "$ to $7 ' 0^{\prime \prime}$ had no ties to the building and no cross bracing between themselves. This was an extremely bad case of inadequate foundation and the building was shifted to a more suitable site rather than repeat the error.

Sub-floor timbering in several cases (more particularly the original camp construction units) was a mixture of various species of timber as well as a variety of sizes. Borer infestation and dampness due to ground proximity caused serious deterioration and increased the difficulties of placing the building back on its foundation for in those buildings which were particularly close to the ground it was extremely difficult to replace the subfloor timbers to give the building adequate stability consistent with keeping the cost of the work within the limits of Insurance and the economic life of a building which would normally be retained in no place other than the West Coast.

\section{(b) Cladding - Extemal and Internal:}

Timber cladding on external faces present some margin of elasticity and, providing adequate bracing was built in correctly, little harm came to the structure. Buildings tied down properly to concrete foundations and adequatly braced, moved little more than $\frac{1}{2}$ and showed very little surface distortion. Evidence of this was seen at the Railway Station houses, school and State Hydro.

On brick veneer houses the bonding of brickwork was fractured horizontally in the main and vertically in addition where large surfaces form one mass the reason for this is not apparent but could be due to extra lateral tension of timber frame and tie acting against the general movement of the brickwork while the building was in motion. Since many of the earthquake movements in Inangahua were upheavals rather than of a swaying motion this could have caused a pull inwards on these occasions. 
Galv. iron cladding remained intact on roofs and walls; so also did the heavy corrugated asbestos sheets - those replaced had been broken by falling chimeys.

Aluminium roofing proved inadequate to withstand movement, the holding nails gashed large slits, and the sheeting sprang up over the small heads of the nails causing severe sheet distortion at the same time.

In this particular case the roof and ceiling are common, being of extremely low pitch. Wracking transferred to this point is more severe than if the roof is a separate section in the form of pitched rafters and purlins, etc. The aluminium roofing has been replaced with longrun corrugated galv. iron, but channel section roofing similar to "Brownbilt" could prove to be more beneficial.

Internal claddings involved two major forms, namely $\frac{1}{2}$ timber lining with scrim and paper and wall boards such as pinex, hardboard and Gibralter board.

In the first case deterioration was caused through non use of dwangs and less bracing due to the use of timber as a lining medium - extensive wracking of intemal walls was noticeable and at least three homes were considered beyond economical repair involving complete stripping, straightening and re-bracing.

In the second case walls are dwanged and substantially braced to minimise cracking joints. Structural movement caused minor disturbance only generally loosening of stopped joints and springing of nails.

\section{(c) ContributoryFactors:}

As mentioned earlier, damage can be caused in several ways, however, certain elements are considered contributing factors which, if taken care of at the proper time after normal routine inspections, would not lead to major damage.

1. Deferred maintenance is by far the worst offender and paint is one of the main deficiencies. Lack of use has allowed many weatherboards, caps, barges and windows to rot or suffer bad deterioration through neglect and in two cases complete walls disintegrated on impact revealing that plumbing pipework held them in place previously.

2. Borer infestation in low level floor timbers accelerated action of dampness similar to a sponge thus causing some piles to disintegrate thereby forming no support for the sub-floor or sub-floor timbers becoming so weak that they no longer gave adequate bearing over the piles.

3. Drainage - With a rainfall in excess of 100" per year, low bearing sub-soil and inadequate surface drainage, pile foundations (and even standard type in reinforced concrete) stand very little chance of remaining true and level without attention being given to providing adequate surface drainage. - This is aggrevated by the use of 400 gal. G.I. roof run-off storage tanks which overilow on to the surrounding area. 
4. Home Repairs - Many alterations, additions and deletions have been carried out by home owners or occupiers wi thout due regard to structural safe-guards - a number of these weaknesses were quickly exposed by the earthquake - some could have caused loss of life if the timing had been delayed.

For all of the points raised. Inangahus is not an isolated case, the faults quoted are general throughout the Coastal area and must contribute towards excessive destruction whenever an upheaval is encountered.

\section{Feasibility of replacement and recommendations}

In an earthquake-prone area, the use of certain materials should be discouraged for reasons of safety, in favour of others which are less liable to damage, or provision made for extra protection. The latter is generally ruled out on cost basis but can be mentioned here to give some indication of precautions considered necessary.

(a) Chimeys - (1) Unreinforced brickwork is dangerous - a single chimney stack projecting $6^{\prime} 0^{\prime \prime}$ above the roof line weighs in excess of $\frac{1}{2}$ a ton - A sarked galv. iron pitched roof will withstand damage caused by this weight providing the iron is in reasonable condition, whereas concrete tiles crumble and penetrate the ceiling lining beneath.

In the case of tiles, some protection can be afforded by decking the top of the ceiling joists in the immediate area of the chimey and using H.R.C. 663 mesh directly below the tile battens on top of the rafters. This would tend to arrest the free fall and material would spread over the decking below.

(2) Brick chimneys with earthenware liners and $\frac{1}{2}$ M. M. rods in the 4 corners are improvements on the unreinforced type as they prevent the brickwork spilling out of the breastwork.

(3) Concrete chimeys poured in situ are by far the safest, however, vertical reinforcing must be continuous and extend from the base block to the top of the chimney in all four corners. In two cases at Inangahua two only rods were discovered and these were short lapped, thereby allowing the stalk to jump sideways from the gathering approx. $2 "$.

(4) Pre-cast concrete masonry units are very suitable, but can be improved by providing four coved pockets on the sides of the surround so that reinforcing rods may extend from the concrete base pad to the top and not just commence at the gathering.

(5) Widespread use has been made in areas outside Inangahua of stainless steel sections extending above the roof line - these can be made to look attractive. They are not unduly expensive as they can be refitted easily if they fall of $f$ and they have been proved efficient.

(b) Foundations - Mention has been made of foundations in various forms but it is of vital importance structurally that a stable base be provided if the building is to withstand severe shock.

Continuous concrete foundations, adequately reinforced, vented and preferably with a 12" footing (or better) will stand the test and in turn prevent major structural distortion to the framework. 
Buildings at Inangahua built to the Code and of good materials suffered minor damage only. - Rain extended the damage to internal linings and decor especially on buildings with tiled roofs.

(c) Chimey Flashings - The tendency to trim too closely to chimey stacks at the roof line causes a scissor-like movement to develop between the ceiling and roof structures. To avoid this a wider clearance say up to $4^{\mathrm{m}}$ between roof timbers and the chimney would reduce the shearing off tendancy and allow more movement for the stack to sway during the vital period.

Flashing can be satisfactorily achieved with galv.iron or similar roof upstand and counter-flashed with lead in the normal way.

(d) Items like sliding doors can prove dangerous, especially those running on the T-Bar track.

Earthenware pipes having cement compo joists have proved too rigid and the present form of rubber rings shows these have definite advantages and lastly, P.V.C. waterpipe is superior to galv.iron with the socket joints P.V.C. is able to stretch slightly - this compensates admirably for the threaded joists which frequently snapped at the connecting points.

There are other minor items which could show improvements but more for individual taste and need not be mentioned here. However, one issue that is of interest to Contractors in particular, is the availability of supplies. Very quickly the local supplies run short and outside assistance is necessary.

To avoid high transport costs and increased local charges for amall or large supplies to individual contractors, a central depot capable of calling on national supplies would save considerable time and money - materials could be of fered at a standard rate to all and chargeable against a specific job - payments, too, could be similarly made through a central pay office. These facilities would be of assistance to the small contractor who is unable to work efficiently without some form of interim payment and psychologically the local inhabitants would be deprived of one contentious topic frequently aired over the bar counter.

\section{General site work}

In some ways the field work was unorthodox by M.O.W. standards, however, to produce some form of expedience as well as efficiency, the normal procedure of specification writing for each job was reduced to a one page Works Schedule itemizing each defect room by room with external work listed similarly.

The items were extended as accurately as possible to give the extent of repairs required so that the Contractor could get all the information he wanted without much trouble and this method was found to work very well.

Minor problems arose through subsequent shakes causing additional damage but satisfactory adjustments were able to be arranged for these.

Advice and supervision were offered free to all who requested our services and many were grateful for the offer. Frequent differences were amicably settled through our arbitrary and tactful discussions. 


\section{Conclusion}

The events at Inangahua have provided a worthwhile testing ground for coordinating the various work forces found necessary to successfully complete such an undertaking under trying conditions. One or two points arising through general observation can be mentioned here :

(a) Submission of plans of proposed new works and alterations to an approved Authority should be insisted on.

(b) There is a definite requirement for at least a visiting Buildings Inspector to check and advise home owners on structural safeguards.

(c) Provision for control of removal of unsightly and sub-standard buildings which are generally considered a structural hazard.

In conclusion the writer expresses appreciation for the co-operation and able assistance so willingly given by the many individuals, professions and trades representatives with whom he and his team were in close contact, for wi thout their help such an undertaking could not have been accomplished to such a successful degree. 